\title{
Regulation of circulating CTRP-2/CTRP-9 and GDF-8/GDF-15 by intralipids and insulin in healthy control and polycystic ovary syndrome women following chronic exercise training
}

Jayakumar Jerobin ${ }^{1 *}$ (D), Manjunath Ramanjaneya ${ }^{1}$, Ilham Bettahi ${ }^{1}$, Raihanath Parammal', Kodappully Sivaraman Siveen ${ }^{2}$, Meis Alkasem?', Myint Aye ${ }^{3}$, Thozhukat Sathyapalan ${ }^{3}$, Monica Skarulis', Stephen L. Atkin ${ }^{4}$ and Abdul Badi Abou-Samra ${ }^{1}$

\begin{abstract}
Background: Polycystic ovary syndrome (PCOS) is associated with obesity, diabetes, and insulin resistance. The circulating C1Q/TNF-related proteins (CTRP-2, CTRP-9) and growth differentiation factors (GDF-8, GDF-15) contribute to glucose and lipid homeostasis. The effects of intralipids and insulin infusion on CTRP-2, CTRP-9, GDF-8 and GDF15 in PCOS and control subjects before and after chronic exercise training were examined.

Methods: Ten PCOS and nine healthy subjects were studied at baseline status and after moderate-intensity chronic exercise training ( $1 \mathrm{~h}$ exercise, 3 times per week, 8 weeks). All participants were infused with $1.5 \mathrm{~mL} / \mathrm{min}$ of saline or intralipids (20\%) for $5 \mathrm{~h}$, and during the last $2 \mathrm{~h}$ of saline or intralipids infusion hyperinsulinemic-euglycemic clamp (HIEC) was performed. CTRP-2, CTRP-9, GDF-8 and GDF-15 levels were measured at 0, 3 and $5 \mathrm{~h}$.

Results: Intralipids dramatically increased CTRP-2 levels in PCOS $(P=0.02)$ and control $(P=0.004)$ subjects, which was not affected by insulin infusion or by exercise. Intralipids alone had no effects on CTRP-9, GDF-8, or GDF-15. Insulin increased the levels of GDF-15 in control subjects $(P=0.05)$ during the saline study and in PCOS subjects $(P=0.04)$ during the intralipid infusion. Insulin suppressed CTRP9 levels during the intralipid study in both PCOS $(P=0.04)$ and control $(P=0.01)$ subjects. Exercise significantly reduced fasting GDF-8 levels in PCOS $(P=0.03)$ and control $(P=0.04)$ subjects; however, intralipids infusion after chronic exercise training increased GDF-8 levels in both PCOS $(P=0.003)$ and control $(P=0.05)$ subjects and insulin infusion during intralipid infusion reduced the rise of GDF-8 levels.

(Continued on next page)
\end{abstract}

\footnotetext{
* Correspondence: JKumar3@hamad.qa

${ }^{1}$ Qatar Metabolic Institute, Department of Medicine and Academic Health System, Hamad Medical Corporation, Doha, Qatar

Full list of author information is available at the end of the article
}

C C The Author(s). 2021 Open Access This article is licensed under a Creative Commons Attribution 4.0 International License, which permits use, sharing, adaptation, distribution and reproduction in any medium or format, as long as you give appropriate credit to the original author(s) and the source, provide a link to the Creative Commons licence, and indicate if changes were made. The images or other third party material in this article are included in the article's Creative Commons licence, unless indicated otherwise in a credit line to the material. If material is not included in the article's Creative Commons licence and your intended use is not permitted by statutory regulation or exceeds the permitted use, you will need to obtain permission directly from the copyright holder. To view a copy of this licence, visit http://creativecommons.org/licenses/by/4.0/. The Creative Commons Public Domain Dedication waiver (http://creativecommons.org/publicdomain/zero/1.0/) applies to the data made available in this article, unless otherwise stated in a credit line to the data. 
(Continued from previous page)

Conclusion: This study showed that exogenous lipids modulate CTRP-2, which might have a physiological role in lipid metabolism. Since chronic exercise training reduced fasting GDF-8 levels; GDF-8 might have a role in humoral adaptation to exercise. GDF-15 and CTRP-9 levels are responsive to insulin, and thus they may play a role in insulin responses.

Keywords: C1Q/TNF related proteins, Growth differentiation factors, Lipid, Insulin, Insulin resistance, Euglycemic clamp, Exercise and polycystic ovary syndrome

\section{Background}

Polycystic Ovary Syndrome (PCOS) is an endocrine and hormonal disorder affecting 15 to $20 \%$ of reproductive age women $[1,2]$. PCOS causes infertility and is associated with obesity, dyslipidemia, insulin resistance (IR), type 2 diabetes (T2D), and cardiovascular risk [3]. Greater than $50 \%$ of the women with PCOS are either obese or overweight, and increased adiposity contributes to decreased sex hormone-binding globulin (SHBG) and elevated androgen production $[4,5]$. IR is common among non-obese PCOS; however, obesity aggravates IR and metabolic abnormalities in PCOS women [6-8].

C1Q/TNF-related proteins (CTRPs) are glycoproteins belonging to the adipokine family, predominantly secreted by adipose tissue that regulates lipid and metabolism of glucose [9]. The adipose tissue expression of CTRP-2 is upregulated in ob/ob mice compared to the lean animals [10]. CTRP-2 knockout mice had higher energy expenditure and metabolic rates leading to adipose tissue lipolysis and lower body weight [11]. CTRP-2 transgenic mice have an enhanced ability to handle a lipid challenge and showed improved insulin tolerance relative to littermate animals [12]. In humans, CTRP-9 levels are reported to be elevated in obese individuals and declined following the weight loss surgery [13, 14]. Elevated circulating CTRP6 levels were observed in PCOS subjects, whereas decreased CTRP12 and CTRP13 levels were observed in PCOS compared to non-PCOS subjects irrespective of obesity $[15,16]$. The elevated triglyceride-glucose and triglyceride/High-density lipoprotein cholesterol (TG/HDL-c) were associated with IR among PCOS women [17]. In L6 myotubes, recombinant CTRP-9 increases fatty oxidation and reduces lipid accumulation in H4IIE hepatocytes [18].

Growth differentiation factors (GDF), namely GDF-8 and GDF-15, are secreted proteins that belongs to the transforming growth factor-beta (TGF- $\beta$ ) superfamily [19]. GDF8 or myostatin plays a key role in skeletal muscle homeostasis, and GDF-8 deficient mice studies had reduced fat accumulation, increased insulin sensitivity, and glucose uptake [20]. Increased GDF-8 expression was found in follicular fluid and this was linked to a lower pregnancy rate in PCOS women undergoing in vitro fertilization (IVF) [21]. In the third trimester, elevated GDF-15 or macrophage inhibitory cytokine-1 (MIC-1) was observed in Chinese pregnant women [22]. The GDF-15 receptor is known as GDNF family receptor $\alpha$-like that promotes weight loss in mice [23, 24]. GDF-15 was shown to be elevated in obese IR subjects and correlated with $\mathrm{C}$-peptide, glucose, insulinogenic index and prehepatic beta-cell function suggesting its role in beta cell function [25]. GDF-15 regulates oxidized low-density lipoprotein induced lipid homeostasis and autophagy in human macrophages associated with atherosclerosis development [26].

Both CTRPs and GDFs are key regulators of glucose and lipid homeostasis; this study was designed to understand the interplay between circulatory CTRP-2/CTRP9 and GDF-8/GDF-15 by insulin, lipid and the effect of exercise in healthy women, and subjects with PCOS.

\section{Methodology \\ Ethics statement}

All the study participants gave written informed consent, and this study was conducted according to the Good Clinical Practice and Declaration of Helsinki. The study was approved by Medical Research Center, Hamad Medical Corporation (RP \#17180/17) and Yorkshire and Humber Ethics Committee, Leeds (10/H1313/44). ISRC TN number: ISRCTN42448814.

\section{Subject selection}

Ten PCOS patients and nine healthy control subjects participated in this study that were BMI and age matched controls. The participants included in the study were non-smokers, not on any regular medications, and did not have any concurrent illness. Control subjects were recruited by adverts within the hospital, whilst PCOS subjects were recruited from the endocrine clinics of Hull Royal Infirmary UK. Rotterdam criteria were used to define PCOS; the presence of two criteria among the three following criteria, hyperandrogenism, oligomenorrhoea and polycystic ovaries on ultrasound [27, 28]. The study participants did not use any drugs with acetylsalicylic acid during the study period. The study participants had a negative pregnancy test before inclusion in the study. The study participants did not modify 
their dietary habits and lifestyle. Subjects with impaired glucose tolerance based on an OGTT were excluded.

\section{Hyperinsulinemic euglycemic clamp (HIEC)}

PCOS subjects were studied after six or more weeks of amenorrhea, and healthy control were studied during the first menstrual cycle week. The protocol included fasting and infusion of normal saline $(1.5 \mathrm{~mL} / \mathrm{min})$ for 5 h. Before starting the euglycemic clamp, the blood samples were drawn from the study participants at the $3 \mathrm{~h}$ time point (of the $5 \mathrm{~h}$ study) for both saline and Intralipid studies. After $3 \mathrm{~h}$ of saline infusion, HIEC was started with the infusion of intravenous insulin at a rate of $80 \mathrm{mU} / \mathrm{m}^{2}$ surfacearea/min for $20 \mathrm{~min}$ followed by 40 $\mathrm{mU} / \mathrm{m}^{2}$ surfacearea $/ \mathrm{min}$ for an additional $100 \mathrm{~min}$. Plasma glucose was clamped at $5 \mathrm{mmol} / \mathrm{L}$ using $20 \%$ dextrose, the rate of which was adjusted according to the arterialized blood glucose measured every $5 \mathrm{~min}$. A week later, the study participants were infused with intralipid $20 \%(1.5 \mathrm{~mL} / \mathrm{min})$ with $0.3 \mathrm{unit} / \mathrm{kg} / \mathrm{min}$ unfractionated heparin sodium for $5 \mathrm{~h}$. During the last $2 \mathrm{~h}$ of intralipid infusion, a $2 \mathrm{~h}$ HIEC was performed. Insulin sensitivity (IS) measurement was assessed by calculating the glucose disposal rate ( $\mathrm{M}$ value, $\mathrm{mg} / \mathrm{kg} / \mathrm{min}$ ).

\section{Chronic exercise training programme}

Chronic exercise training was undertaken as explained [29]. Within a week following the baseline assessment, participants began attending 3 supervised exercise sessions per week for 8 weeks. Where possible, each session was $1 \mathrm{~h}$ in duration depending on their ability to complete the sessions with no complications. The programme used either a Woodway ELG55 motorized treadmill (Woodway, Weil an rhein, Germany), or a HP Cosmos Pulsar Treadmill (H/P/Cosmos) with the same protocol. Participants performed all sessions on a motorized treadmill working at or as closely as possible to $60 \%$ $\mathrm{VO}_{2 \text { max. }} \mathrm{VO}_{2} / \mathrm{kg}$ was measured after the warm-up, which lasted for $5 \mathrm{~min}$ at $4.5 \mathrm{~km}^{-1}$ and for $10 \mathrm{~min}$ to confirm the appropriate exercise intensity. The intensity of exercise was then adjusted by altering the speed of the treadmill if this value was not within $\pm 2.5 \%$ of the target oxygen uptake. Following $10 \mathrm{~min}$ gas collection, the facemask was withdrawn with the speed of the treadmill remaining as it was. A further gas collection was made at $40 \mathrm{~min}$ to confirm the desired intensity for a $5 \mathrm{~min}$ period. If this intensity was out of range, then the treadmill speed was once again altered if required. Heart rate (HR) and rate of perceived exertion (RPE) [30] were monitored every $15 \mathrm{~min}$ throughout the session. If the participants felt that they could not continue with the exercise for reasons such as injury or fatigue, they were able to stop at any time if necessary. Likewise, if the participant needed to recover from fatigue, the intensity was reduced for a period of time; otherwise the intensity remained at the level pre-determined. Each session ended with a $5 \mathrm{~min}$ cool down at $4.5 \mathrm{~km}^{\cdot} \mathrm{h}^{-1}$ and participants would then be free to leave once HR returned to within $120 \%$ of basal levels. The participants in the study were not asked to alter their diet in any way and were to continue as normal with their calorie consumptions throughout the chronic exercise training programme. During exercise session visits, fluid intake was permitted ad libitum.

After 8 weeks chronic exercise training intervention within a week, saline and HIEC clamp were performed, and the following week intralipid and HIEC clamp were performed in all the study participants (Fig. 1).

\section{Biochemical and hormonal parameters measurement}

Plasma glucose, triglycerides (TG), total cholesterol (TCH), HDL, and Alanine transaminase (ALT) were measured by SynchonLX20 analyzer, High Wycombe, UK. LDL-c levels were performed by the Friedwald equation. The enzymatic calorimetric method was used to measure non-esterified fatty acids (NEFA) in Konelab20 autoanalyzer, Swedesboro, NJ, USA. Chemiluminescent immunoassay kit (Euro/DPC, Llanberis, UK) was used to measure insulin levels. The SHBG was measured using DPC immulite 2000 analyzer. Testosterone levels were measured by HPLC/tandem mass spectrometry (Waters Corporation, Manchester, UK). Free androgen index (FAI) was performed by using the formula:100*testosterone/ SHBG. Waist to Hip ratio (WHR) is calculated by waist divided by the hip measurement (Waist/Hip).

CTRP-2 was measured using ELISA kits obtained from MyBioSource, San Diego, CA, USA with a minimum detectable dose (MDD) $0.039 \mathrm{ng} / \mathrm{mL}$ and detection range 0.156-10 ng/mL (intra-assay CV: < 8\% and inter-assay < 10\%). CTRP-9 levels were measured by ELISA kits obtained from MyBioSource, San Diego, CA, USA, with sensitivity less than $0.412 \mathrm{ng} / \mathrm{mL}$ and detection range $0.78-50 \mathrm{ng} / \mathrm{mL}$ (intraassay $\mathrm{CV}$ : $<5.9 \%$ and inter-assay CV: 9.5\%). GDF8/myostatin was measured using a commercially available Quantitine kit obtained from R\&D Systems, Minneapolis, MN, USA with minimum detectable dose (MDD) ranged from $0.922-5.32 \mathrm{pg} / \mathrm{mL}$ and assay range $31.3-2000 \mathrm{pg} / \mathrm{mL}$ (intra-assay $\mathrm{CV}<5.4 \%$ and inter-assay variation $<6.0)$. GDF-15 was measured using ELISA kits obtained from Thermo Scientific, Frederick, MD, USA with sensitivity $2 \mathrm{pg} / \mathrm{mL}$ and detection range $1.10-800 \mathrm{pg} / \mathrm{mL}$ (intra-assay $\mathrm{CV}<10 \%$ and inter-assay $\mathrm{CV}<12 \%)$. All the samples measured gave values within the dynamic range of the assays.

\section{Statistical analysis}

Statistical analysis was performed using SPSS 22.0 software and Graphpad Prism 5. Two-way ANOVA with 


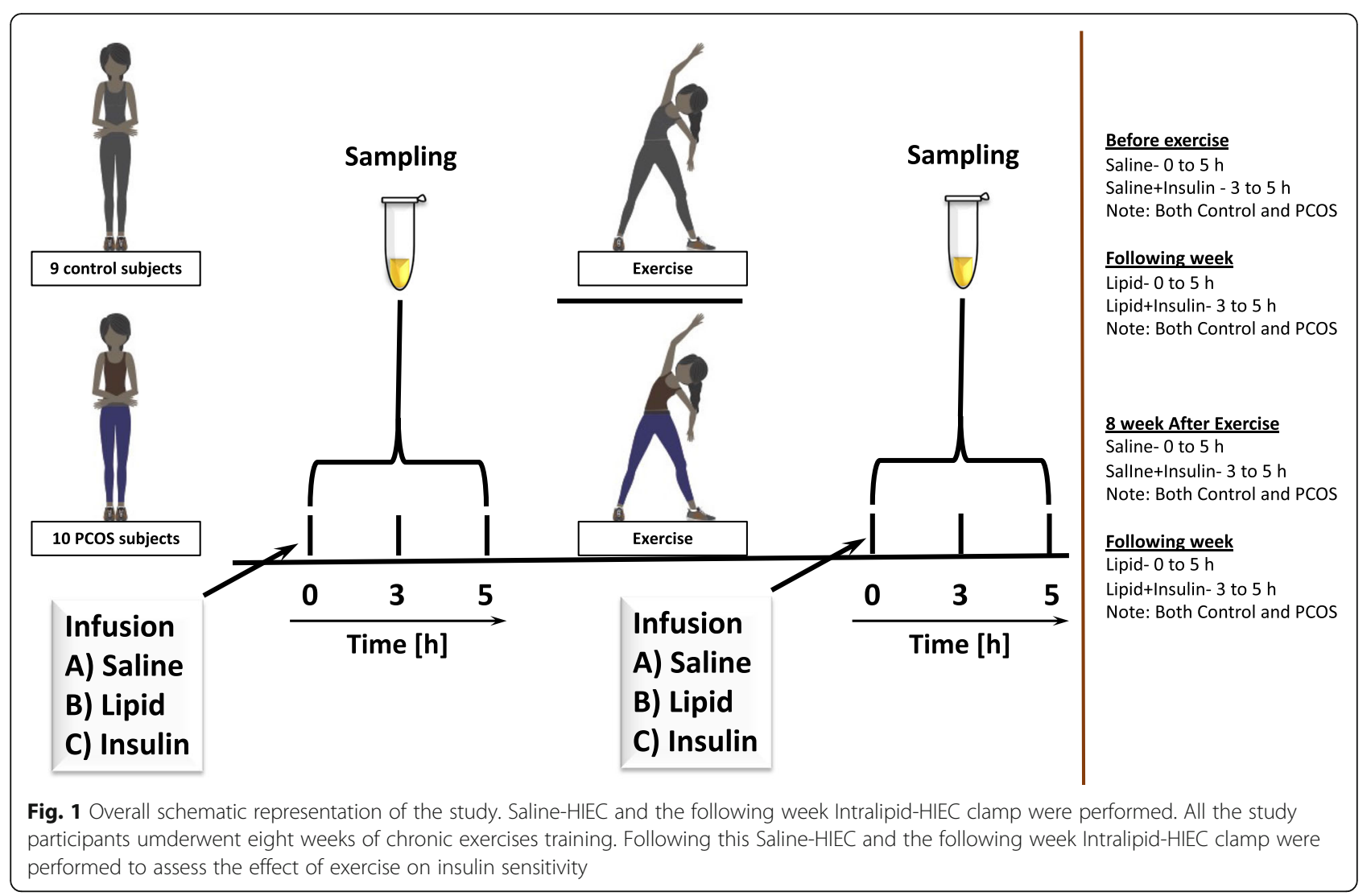

Tukey's multiple comparison test was performed to indicate significant differences between the variables. The Student's unpaired t-test was performed to determine the significance between the groups. The Student's paired t-test was performed to determine the significance within the control and PCOS subjects. The mean difference was calculated from the difference between the values after the chronic exercise training and before chronic exercise training expressed as mean and 95\% CI. Pearson correlation coefficient was performed to study the correlations between circulating CTRP2, CTRP9, GDF-8, and GDF-15 with anthropometric and biochemical variables. The data are presented as mean \pm standard deviation (SD) for normally distributed variables.

\section{Results}

Baseline characteristics of CTRP and GDF levels in healthy control and PCOS subjects

The baseline characteristics of the study subjects have been previously reported [27, 31]. In brief, the PCOS subjects were overweight, and other clinical variables that were similar between the control and PCOS subjects include BMI, lipid profiles (TCH, TG, HDL, and LDL), SBP, DBP, and FPG. In PCOS subjects, significantly elevated $\operatorname{ALT}(P=0.03)$, HOMA-IR $(P=0.05)$, and FAI $(P=0.002)$ whereas decreased SHBG $(P=0.001)$ levels were observed compared to healthy control (Table 1) [27]. Circulating CTRP-2 $(P=0.68)$, CTRP-9 $(P=0.49)$, GDF-8 $(P=0.25)$ and GDF-15 $(P=0.38)$ levels were similar in healthy control and PCOS subjects (Fig. 2).

\section{Effects of insulin infusion}

The plasma concentration of CTRP-2, CTRP-9, GDF-8, and GDF-15 were stable during the $3 \mathrm{~h}$ of saline infusion. Infusion of insulin for $2 \mathrm{~h}$ after the $3 \mathrm{~h}$ of saline infusion significantly decreased GDF-8 levels in healthy control $(P=0.03)$ and PCOS women $(P=0.04)$ and significantly increased GDF-15 in healthy control $(P=0.05)$ (Table 2). Insulin infusion did not affect either plasma CTRP-2 and CTRP-9 levels in both groups.

\section{Effects of Intralipid and insulin infusion}

Intralipid infusion for $3 \mathrm{~h}$ significantly increased CTRP-2 levels in healthy control $(P=0.004)$ and PCOS $(P=0.02)$ women; but had no effects on CTRP-9, GDF-8 or GDF15 (Table 2). Co-infusion of insulin at 3-5 h significantly reduced CTRP-9 levels in healthy control $(P=$ $0.01)$ and PCOS $(P=0.04)$ women, increased GDF-15 levels in PCOS women $(P=0.04)$; but had no effects on CTRP-2 levels (Table 2). 
Table 1 Anthropometric, biochemical and hormonal measurement (means \pm SD) of controls and PCOS subjects

\begin{tabular}{llll}
\hline Clinical Variables & $\begin{array}{l}\text { Control } \\
(\boldsymbol{n}=\mathbf{9})\end{array}$ & $\begin{array}{l}\text { PCOS } \\
(\boldsymbol{n}=\mathbf{1 0})\end{array}$ & $\boldsymbol{P}$-value \\
\hline Age (years) & $24.8 \pm 6.3$ & $28.2 \pm 7.1$ & 0.29 \\
BMI (kg/m $)^{2}$ & $25.4 \pm 5.8$ & $29.9 \pm 5.4$ & 0.09 \\
Waist (cm) & $79.6 \pm 13.6$ & $91.7 \pm 12.7$ & 0.06 \\
Hip (cm) & $99.1 \pm 14.7$ & $109.9 \pm 11.8$ & 0.09 \\
WHR & $0.8 \pm 0.1$ & $0.8 \pm 0.1$ & 0.24 \\
SBP (mmHg) & $117.3 \pm 6.2$ & $118.8 \pm 10.2$ & 0.71 \\
DBP (mmHg) & $74.2 \pm 8.5$ & $76.2 \pm 7.8$ & 0.60 \\
Free androgen index & $1.9 \pm 2.1$ & $6.6 \pm 3.2$ & 0.002 \\
SHBG (nmol/L) & $72.6 \pm 29.8$ & $26.0 \pm 19.5$ & 0.001 \\
Testosterone (nmol/L) & $0.9 \pm 0.3$ & $1.3 \pm 0.6$ & 0.12 \\
Total cholesterol (mmol/L) & $4.6 \pm 0.8$ & $4.1 \pm 0.7$ & 0.14 \\
Triglycerides (mmol/L) & $0.8 \pm 0.2$ & $1.3 \pm 0.8$ & 0.08 \\
HDL-c (mmol/L) & $1.5 \pm 0.5$ & $1.3 \pm 0.4$ & 0.29 \\
LDL-c (mmol/L) & $2.7 \pm 0.6$ & $2.3 \pm 0.5$ & 0.17 \\
ALT (IU/L) & $17.3 \pm 5.8$ & $29.8 \pm 13.9$ & 0.03 \\
FPG (mmol/L) & $4.7 \pm 0.6$ & $4.7 \pm 0.5$ & 0.93 \\
NEFA ( $\boldsymbol{\mu m o l / L ) ~}$ & $505.2 \pm 180.2$ & $482.9 \pm 144.4$ & 0.77 \\
HOMA-IR & $1.4 \pm 0.8$ & $2.7 \pm 1.7$ & 0.05 \\
\hline Vas are & & &
\end{tabular}

Values are represented as means + SD

$B M I$ Body Mass Index, WHR Waist $\bar{H}$ ip ratio, SBP Systolic blood pressure, DBP Diastolic blood pressure, SHBG Sex hormone binding globulin, TC Total cholesterol, $L D L-c$ Low density lipoprotein cholesterol and $H D L-C$ High density lipoprotein cholesterol and TG triglyceride, $A L T$ alanine transferase, FPG fasting plasma glucose, NEFA non-esterified free fatty acids, HOMA-IR Homeostatic model assessment of insulin resistance

Student's unpaired t-test was done between control and PCOS subjects

$P<0.05$ is considered to be statistically significant

\section{Effect of eight-week chronic exercise training}

Chronic exercise training improved the overall fitness of the participants with $\mathrm{VO}_{2}$ max improvement [27], but no weight changes were observed following exercise. Chronic exercise training improved insulin sensitivity in both PCOS and control subjects equally, so there was no difference between groups [27, 32].

The effects of chronic exercise training on basal levels of the CTRPs/GDFs were examined. Chronic exercise training significantly reduced basal GDF- 8 levels in healthy control $(P=0.04)$ and PCOS subjects $(P=0.03)$ (Table 3) but did not have significant effects on basal CTRP-2, CTRP-9, and GDF-15 levels.

The modulatory effects of chronic exercise training on intralipids and insulin infusions were studied in these subjects (Table 4). The stimulatory effects of intralipid infusion on CTRP-2 observed before chronic exercise training was also seen in the study after chronic exercise training. In addition, intralipid increased the levels of GDF-8 after chronic exercise training in both the healthy control $(P=0.05)$ and PCOS women $(P=0.003)$. The increase in GDF-8 levels observed in PCOS women during infusion of intralipids was significantly decreased due to co-infusion with insulin $(P=0.03)$.

The level of GDF-15 tends to decrease during the $3 \mathrm{~h}$ of saline and intralipid infusions after chronic exercise training; the decrease was significant in saline control group $(P=0.03)$; co-infusion of insulin reversed this decline in GDF-15 in the saline control group $(P=0.02)$ and intralipid PCOS women $(P=0.01)$ (Table 4$)$.

\section{Correlation analysis of CTRP2/ CTRP9 and GDF-8/GDF-15 with covariates}

The CTRP-2/9 and GDF-8/15 association with baseline biochemical, clinical, and hormonal parameters was performed using the Pearson correlation coefficient (Table 5). In PCOS women, CTRP-2 levels correlated positively with testosterone $(r=0.71, P=0.02)$ and CTRP-9 correlated negatively with GDF-15 $(r=-0.77, P=0.01)$. In healthy controls, CTRP-2 negatively correlated with WHR $(r=-$ $0.75, P=0.02$ ).

GDF-8 correlated positively with testosterone $(r=0.64$, $P=0.05)$ levels and LDL-c $(r=0.74, P=0.01)$ in PCOS women. However, GDF-15 correlated positively with LDL-c $(r=0.81, P=0.01)$ in healthy controls. In PCOS women, GDF-15 correlated positively with SBP $(r=0.65$, $P=0.04)$ and FPG $(r=0.68, P=0.03)$.

\section{Discussion}

Infusion of lipids during HIEC is reported to shift the fuel source from glucose to lipids for cellular oxidative processes. The dramatic increase in TG reverses insulin inhibition of lipid oxidation and blunts insulin-stimulated glucose utilization $[33,34]$ that is consistent with the finding of reduced IS during intralipid infusion. Elevated FFA levels following intralipid administration are secondary to lipase-mediated hydrolysis of TG. Since lipase is inhibited by insulin, FFA levels were reduced during the HIEC in all subjects both during saline and intralipid infusion [35, 36] that is in accord with previous reports that insulin reduced NEFA in both groups during the first study period and during the intralipid infusion [31].

Intralipid infusion increases the plasma levels of CTRP2 and raises the possibility that CTRP- 2 may be regulated by endogenous lipid, or that CTRP-2 may play a physiological role in lipid metabolism. Consistent with these hypotheses is the finding in animal models of CTRP-2 deficiency [11] and CTRP-2 overexpression [12]. CTRP-2 knock-out mice showed elevated energy expenditure, and upregulation of lipolytic enzymes [11] whereas CTRP-2 transgenic mice subjected to diet-induced obesity showed improved lipid and insulin tolerance [12]. In response to lipid infusion, CTRP-2 transgenic mice have a greater capacity to clear an acute increase in FFA compared to WT controls. During the fasting state, CTRP-2 transgenic mice 

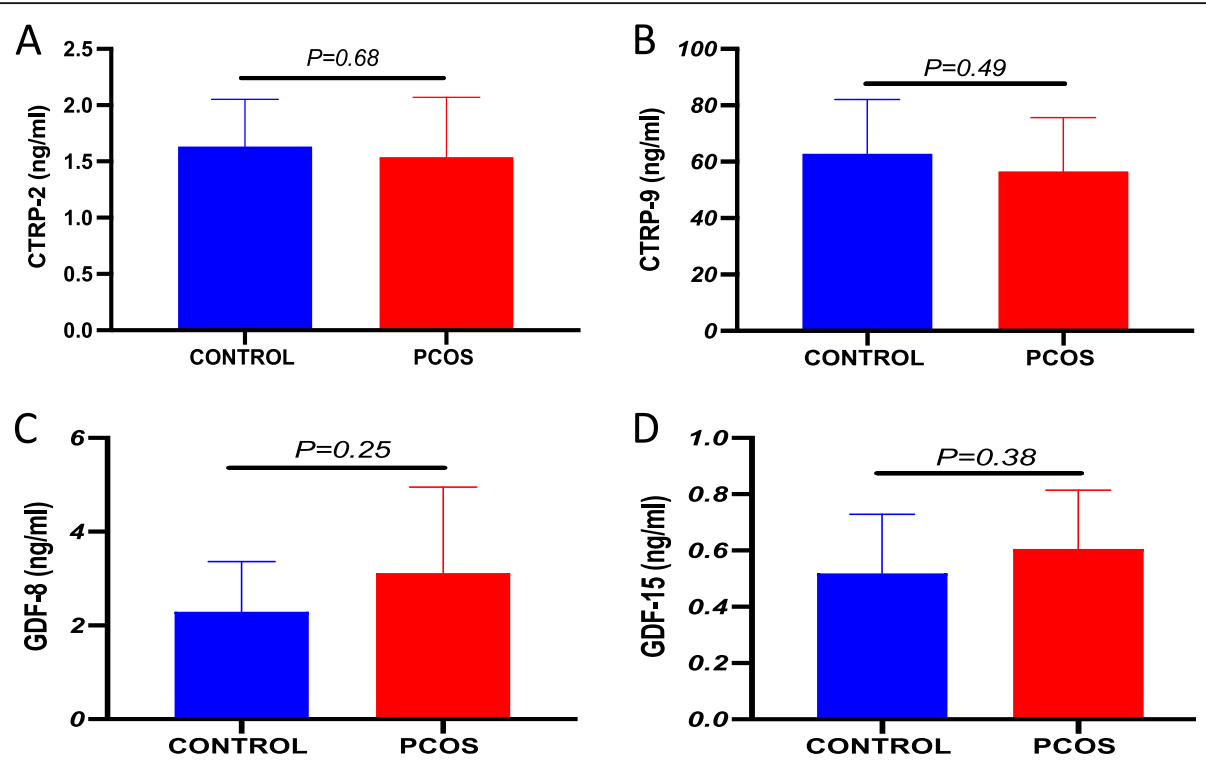

Fig. 2 CTRP2, CTRP9,GDF-8 and GDF-15 levels in healthy controls and PCOS women. a CTRP-2; b CTRP-9; c GDF-8; d GDF-15. P<0.05 is found to be statistically significant. No significant differences in CTRP-2, CTRP-9, GDF-8 and GDF-15 levels were observed between control and PCOS women. Student's unpaired t-test was done to determine the significance between the control and PCOS subjects

can mobilize FFA in adipose tissue via the b3-adrenergic receptor [12]. This suggests that in humans, CTRP-2 might play a physiological role in lipid and energy metabolism: and that a negative feedback mechanism between TG and CTRP-2 may physiologically regulate their concentrations.
In cultured myotubes, CTRP-2 activates AMPK and acetyl-coA resulting in glycogen accumulation, glucose uptake, and fatty acid oxidation [12, 37]. An insulin tolerance test (ITT) in CTRP-2 transgenic mice shows an enhanced glucose disposal rate indicating improved insulin action compared to wild-type (WT) mice [12]. The

Table 2 Effects of insulin and intralipid infusion in control and PCOS subjects before exercise

\begin{tabular}{|c|c|c|c|c|c|}
\hline \multicolumn{2}{|l|}{ Study Design $\rightarrow$} & \multicolumn{2}{|c|}{$\begin{array}{l}\text { Saline Study } \\
\text { - Saline: } 0 \text { to } 5 \mathrm{H} \\
\text { - Insulin and glucose: } 3 \text { to } 5 \mathrm{H}\end{array}$} & \multicolumn{2}{|c|}{$\begin{array}{l}\text { Intralipid Study } \\
\text { - Intralipid: } 0 \text { to } 5 \mathrm{H} \\
\text { - Insulin and glucose: } 3 \text { to } 5 \mathrm{H}\end{array}$} \\
\hline CTRPs \& GDFs & Time $(\mathrm{H})$ & $\begin{array}{l}\text { Control } \\
(N=9)\end{array}$ & $\begin{array}{l}\text { PCOS } \\
(N=10)\end{array}$ & $\begin{array}{l}\text { Control } \\
(N=9)\end{array}$ & $\begin{array}{l}\text { PCOS } \\
(N=10)\end{array}$ \\
\hline \multirow[t]{3}{*}{ CTRP2 (ng/mL) } & 0 & $1.6 \pm 0.4$ & $1.5 \pm 0.5$ & $1.9 \pm 0.6$ & $1.7 \pm 0.7$ \\
\hline & $3 \mathrm{H}$ & $1.6 \pm 0.6$ & $1.8 \pm 0.7$ & $4.9 \pm 2.4^{a, d}$ & $3.9 \pm 2.2^{a, d}$ \\
\hline & $5 \mathrm{H}$ & $1.9 \pm 1.0$ & $2.1 \pm 1.0$ & $4.7 \pm 1.7^{a, d}$ & $4.4 \pm 1.9^{a, d}$ \\
\hline \multirow[t]{3}{*}{ CTRP9 (ng/mL) } & 0 & $62.8 \pm 19.2$ & $56.6 \pm 19.1$ & $62.9 \pm 23.1$ & $56.9 \pm 23.1$ \\
\hline & $3 \mathrm{H}$ & $65.3 \pm 18.9$ & $58.4 \pm 15.4$ & $69.4 \pm 23.2$ & $65.4 \pm 27.2$ \\
\hline & $5 \mathrm{H}$ & $70.3 \pm 24.9$ & $57.3 \pm 15.7$ & $57.8 \pm 22.8^{b}$ & $53.8 \pm 30.9^{b}$ \\
\hline \multirow[t]{3}{*}{ GDF8 (ng/mL) } & 0 & $2.3 \pm 1.1$ & $3.1 \pm 1.8$ & $2.8 \pm 1.1$ & $2.8 \pm 1.2$ \\
\hline & $3 \mathrm{H}$ & $2.0 \pm 0.8$ & $2.7 \pm 1.2$ & $2.8 \pm 1.0$ & $2.6 \pm 1.1$ \\
\hline & $5 \mathrm{H}$ & $1.7 \pm 0.7^{a}$ & $2.3 \pm 0.9^{a}$ & $2.4 \pm 0.7^{d}$ & $2.6 \pm 1.0$ \\
\hline \multirow[t]{3}{*}{ GDF15 (ng/mL) } & 0 & $0.5 \pm 0.2$ & $0.6 \pm 0.2$ & $0.7 \pm 0.4$ & $0.7 \pm 0.3$ \\
\hline & $3 \mathrm{H}$ & $0.8 \pm 0.5$ & $0.7 \pm 0.2$ & $0.7 \pm 0.4$ & $0.7 \pm 0.2$ \\
\hline & $5 \mathrm{H}$ & $0.9 \pm 0.6^{a}$ & $0.8 \pm 0.2$ & $1.2 \pm 1.0$ & $1.2 \pm 0.8^{b}$ \\
\hline
\end{tabular}

The data are represented as Mean \pm SD

Statistical significance $(P<0.05)$ is shown in the table with superscripts $a, b, c$ and $d$

$a$ compares $3 \mathrm{H}$ or $5 \mathrm{H}$ versus $0 ; b$ compares $5 \mathrm{H}$ versus $3 \mathrm{H} ; c$ compares $\mathrm{PCOS}$ values versus respective control values; and $d$ compares intralipid values versus respective saline values

CTRPs C1Q/TNF related proteins, GDFs Growth differentiation factors

$a, b$ and $d$ : Student's paired t-test; $c$ : Two-way ANOVA 
Table 3 Effect of exercise on CTRP2, CTRP9, GDF-8 and GDF-15 levels

\begin{tabular}{lllll}
\hline CTRPs \& GDFs & $\begin{array}{l}\text { Control Subjects } \\
(\boldsymbol{N}=\mathbf{9})\end{array}$ & $\boldsymbol{P}$-value & $\begin{array}{l}\text { PCOS Subjects } \\
(\boldsymbol{N}=\mathbf{1 0})\end{array}$ & $\boldsymbol{P}$-value \\
\hline CTRP-2, ng/mL & $0.02(-0.27,0.32)$ & 0.85 & $0.19(-0.18,0.56)$ & 0.28 \\
CTRP-9, ng/mL & $-2.88(-31.17,25.42)$ & 0.82 & $-2.31(-14.72,10.09)$ & 0.68 \\
GDF-8, ng/mL & $-1.03(-1.99,-0.06)$ & 0.04 & $-1.54(-2.91,-0.17)$ & 0.03 \\
GDF-15, ng/mL & $-0.01(-0.16,0.14)$ & 0.84 & $0.03(-0.19,0.25)$ & 0.75 \\
\hline
\end{tabular}

The data are expressed as the difference between the values after and before exercise expressed as mean and $(95 \% \mathrm{Cl})$

CTRPs C1Q/TNF related proteins, GDFs Growth differentiation factors

Student's paired t-test was done to determine the significant difference within control and PCOS subjects respectively

insulin-stimulated glucose disposal rate was lower in PCOS subjects during lipid infusion and an acute increase in NEFA with intralipids lowered the glucose disposal rate in the skeletal muscle indicating IR in PCOS subjects compared to BMI and age-matched controls [27]. Lifestyle modifications with increased physical activity reduce metabolic complications in PCOS subjects [38]. During the lipid infusion, women with PCOS who had undertaken the exercise training had an improved glucose disposal rate. The improvement in IR following chronic exercise training is reduced fat metabolites and increased fat oxidation [27, 32]. No changes in CTRP-2 levels were seen following chronic exercise training, but this was not surprising since no body weight changes were observed, and CTRP-2 levels are related to changes in body weight [12]. As CTRP-2 is not affected by insulin levels then the change in insulin sensitivity would also not affect CTRP-2 levels.
Circulating CTRP-9 levels are significantly increased in patients with T2D and strongly associated with IR [13]. CTRP-9 levels were correlated positively with serum concentrations of LDL-c and total cholesterol in PCOS subjects [39]. Elevated CTRP2 and decreased CTRP9 are associated with the risk and progression coronary artery disease [40-42]. In this study we did not observe any significant changes of CTRP-2 and CTRP-9 in either controls or PCOS subjects. Targeted CTRP-9 deletion in animal models resulted in increased fasting insulin levels, decreased insulin sensitivity, and food intake. Overexpression of CTRP-9 resulted in improved insulin sensitivity by reducing in fasting glucose and insulin levels [18]. CTRP-9 deletion resulted in decreased AMPK activation in skeletal muscles [43]. Treatment with recombinant CTRP-9 enhanced fatty oxidation through the reduced accumulation of lipid accumulation and AMPK activation in hepatocytes [18]. This study on

Table 4 Effects of insulin and intralipid infusion in control and PCOS subjects after exercise

\begin{tabular}{|c|c|c|c|c|c|}
\hline \multicolumn{2}{|l|}{ Study Design $\rightarrow$} & \multicolumn{2}{|c|}{$\begin{array}{l}\text { Saline Study } \\
\text { - Saline: } 0 \text { to } 5 \mathrm{H} \\
\text { - Insulin and glucose: } 3 \text { to } 5 \mathrm{H}\end{array}$} & \multicolumn{2}{|c|}{$\begin{array}{l}\text { Intralipid Study } \\
\text { - Intralipid: } 0 \text { to } 5 \mathrm{H} \\
\text { - Insulin and glucose: } 3 \text { to } 5 \mathrm{H}\end{array}$} \\
\hline Clinical Variables & Time $(\mathbf{H})$ & $\begin{array}{l}\text { Control } \\
(N=9)\end{array}$ & $\begin{array}{l}\text { PCOS } \\
(N=10)\end{array}$ & $\begin{array}{l}\text { Control } \\
(N=9)\end{array}$ & $\begin{array}{l}\text { PCOS } \\
(N=10)\end{array}$ \\
\hline \multirow[t]{3}{*}{ CTRP2 (ng/mL) } & 0 & $1.7 \pm 0.6$ & $1.7 \pm 0.6$ & $1.7 \pm 0.5$ & $1.6 \pm 0.6$ \\
\hline & $3 \mathrm{H}$ & $1.7 \pm 0.6$ & $1.8 \pm 0.7$ & $3.2 \pm 1.4^{a, d}$ & $3.4 \pm 1.2^{a, d}$ \\
\hline & $5 \mathrm{H}$ & $2.1 \pm 1.4$ & $2.3 \pm 0.8$ & $3.6 \pm 1.6^{a}$ & $3.5 \pm 1.1^{a, d}$ \\
\hline \multirow[t]{3}{*}{ CTRP9 (ng/mL) } & 0 & $59.9 \pm 37.4$ & $54.3 \pm 23.9$ & $66.1 \pm 27.7$ & $65.8 \pm 17.5$ \\
\hline & $3 \mathrm{H}$ & $80.4 \pm 49.8$ & $70.1 \pm 17.6$ & $67.7 \pm 34.8$ & $67.5 \pm 22.3$ \\
\hline & $5 \mathrm{H}$ & $74.5 \pm 49.2$ & $69.7 \pm 24.4$ & $60.1 \pm 44.9$ & $59.5 \pm 14.9$ \\
\hline \multirow[t]{3}{*}{ GDF8 (ng/mL) } & 0 & $1.3 \pm 0.4$ & $1.6 \pm 0.6$ & $1.6 \pm 0.9$ & $1.6 \pm 0.9$ \\
\hline & $3 \mathrm{H}$ & $1.2 \pm 0.3$ & $1.5 \pm 0.4$ & $2.5 \pm 0.8^{a, d}$ & $2.6 \pm 1.0^{a, d}$ \\
\hline & $5 \mathrm{H}$ & $1.0 \pm 0.3^{a, b}$ & $1.3 \pm 0.5$ & $2.1 \pm 0.9^{d}$ & $2.2 \pm 1.1^{a, b, c}$ \\
\hline \multirow[t]{3}{*}{ GDF15 (ng/mL) } & 0 & $0.5 \pm 0.3$ & $0.6 \pm 0.2$ & $0.7 \pm 0.2$ & $0.7 \pm 0.2$ \\
\hline & $3 \mathrm{H}$ & $0.3 \pm 0.2^{a}$ & $0.6 \pm 0.5$ & $0.5 \pm 0.4$ & $0.5 \pm 0.4$ \\
\hline & $5 \mathrm{H}$ & $0.5 \pm 0.3^{b}$ & $0.9 \pm 0.4^{b, c}$ & $0.9 \pm 0.9$ & $1.1 \pm 0.9^{b}$ \\
\hline
\end{tabular}

The data are represented as Mean \pm SD

Statistical significance $(P<0.05)$ is shown in the table with superscripts $a, b, c$ and $d$

$a$ compares $3 \mathrm{H}$ or $5 \mathrm{H}$ versus $0 ; b$ compares $5 \mathrm{H}$ versus $3 \mathrm{H} ; c$ compares $\mathrm{PCOS}$ values versus respective control values at different time point; and $d$ compares

intralipid values versus respective saline values

CTRPs C1Q/TNF related proteins, GDFs Growth differentiation factors

$a, b$ and $d$ : Student's paired t-test, c: Two-way ANOVA 
Table 5 Pearson correlation coefficient of CTRP2, CTRP9, GDF-8 and GDF-15 with anthropometric and biochemical variables

\begin{tabular}{|c|c|c|c|c|c|c|c|c|}
\hline \multirow{3}{*}{$\begin{array}{l}\text { CLINICAL } \\
\text { VARIABLES }\end{array}$} & \multicolumn{2}{|l|}{ CTRP-2 } & \multicolumn{2}{|l|}{ CTRP-9 } & \multicolumn{2}{|l|}{ GDF-8 } & \multicolumn{2}{|l|}{ GDF-15 } \\
\hline & $\begin{array}{l}\text { Control } \\
(N=9)\end{array}$ & $\begin{array}{l}\text { PCOS } \\
(N=10)\end{array}$ & $\begin{array}{l}\text { Control } \\
(N=9)\end{array}$ & $\begin{array}{l}\text { PCOS } \\
(N=10)\end{array}$ & $\begin{array}{l}\text { Control } \\
(N=9)\end{array}$ & $\begin{array}{l}\text { PCOS } \\
(N=10)\end{array}$ & $\begin{array}{l}\text { Control } \\
(N=9)\end{array}$ & $\begin{array}{l}\text { PCOS } \\
(N=10)\end{array}$ \\
\hline & $r$ & $r$ & $r$ & $r$ & $r$ & $r$ & $r$ & $r$ \\
\hline CTRP-2 & 1 & 1 & -0.49 & -0.01 & -0.02 & 0.16 & -0.43 & 0.07 \\
\hline CTRP-9 & -0.49 & -0.01 & 1 & 1 & -0.001 & 0.58 & 0.44 & $-0.77^{*}$ \\
\hline GDF-8 & -0.02 & 0.16 & -0.001 & 0.58 & 1 & 1 & -0.17 & -0.46 \\
\hline GDF-15 & -0.43 & 0.07 & 0.44 & $-0.77^{*}$ & -0.17 & -0.46 & 1 & 1 \\
\hline Age & -0.60 & -0.33 & 0.41 & -0.03 & 0.30 & -0.24 & 0.59 & -0.40 \\
\hline BMI & -0.29 & 0.39 & -0.35 & -0.09 & -0.10 & 0.20 & 0.55 & 0.08 \\
\hline Waist & -0.24 & 0.38 & -0.38 & -0.003 & -0.01 & 0.14 & 0.51 & 0.10 \\
\hline Hip & 0.05 & 0.48 & -0.62 & -0.15 & -0.14 & 0.02 & 0.35 & 0.19 \\
\hline WHR & $-0.75^{*}$ & 0.05 & 0.45 & 0.21 & 0.26 & 0.24 & 0.46 & -0.08 \\
\hline SBP & -0.26 & 0.19 & -0.18 & -0.58 & 0.14 & -0.50 & 0.48 & $0.65^{*}$ \\
\hline DBP & 0.21 & 0.06 & -0.50 & -0.39 & 0.10 & 0.24 & 0.38 & 0.51 \\
\hline Testosterone & -0.09 & $0.71^{*}$ & 0.16 & 0.24 & -0.12 & $0.64^{*}$ & -0.40 & -0.12 \\
\hline FAI & -0.04 & 0.31 & -0.34 & 0.06 & -0.52 & 0.39 & -0.11 & -0.44 \\
\hline SHBG & 0.14 & -0.05 & 0.45 & -0.20 & 0.30 & -0.22 & -0.15 & 0.62 \\
\hline TC & 0.05 & -0.01 & 0.22 & 0.40 & 0.26 & 0.46 & 0.44 & -0.34 \\
\hline TG & -0.39 & -0.13 & 0.16 & 0.35 & 0.41 & -0.08 & 0.57 & -0.15 \\
\hline HDL & 0.20 & -0.25 & 0.23 & 0.23 & 0.52 & -0.12 & -0.30 & -0.29 \\
\hline LDL-c & -0.24 & 0.24 & 0.11 & 0.17 & -0.06 & $0.74^{*}$ & $0.81^{*}$ & -0.15 \\
\hline FPG & -0.20 & -0.37 & -0.15 & -0.51 & -0.12 & -0.26 & 0.46 & $0.68^{*}$ \\
\hline ALT & 0.03 & 0.37 & -0.35 & 0.04 & 0.45 & 0.41 & -0.26 & 0.04 \\
\hline NEFA & 0.16 & -0.56 & -0.33 & -0.47 & 0.47 & -0.27 & 0.10 & 0.34 \\
\hline HOMA-IR & -0.62 & 0.002 & -0.23 & 0.12 & -0.42 & 0.56 & 0.27 & 0.005 \\
\hline
\end{tabular}

$r$ is Pearson correlation coefficient

CTRPs C1Q/TNF related proteins, GDFs Growth differentiation factors, BMI Body Mass Index, WHR Waist Hip ratio, SBP Systolic blood pressure, DBP Diastolic blood pressure, SHBG Sex hormone binding globulin, TC Total cholesterol, LDL-c Low density lipoprotein cholesterol and HDL-c High density lipoprotein cholesterol and TG triglyceride, ALT alanine transferase, FPG fasting plasma glucose, NEFA non-esterified free fatty acids, HOMA-IR Homeostatic model assessment of insulin resistance

${ }^{*} P<0.05$ is considered to be statistically significant

human did not show any differences in CTRP-9 levels between control and PCOS women or significant changes in CTRP-9 levels after insulin or intralipid infusion; Therefore, this study did not support an important role for CTRP-9 in human subjects in terms of homeostasis during HIEC, hypertriglyceridemia, and chronic exercise training.

In PCOS women, increased GDF-8 levels were associated with increased BMI, FPG and decreased LDL-c was associated with increased GDF-8 levels [44, 45]. The increased skeletal muscle and circulating GDF- 8 levels are due to physical inactivity, resulting in metabolic deterioration leading to the progression from IR to T2DM $[46,47]$. Aerobic exercise decreases the skeletal and circulatory GDF-8 levels, thus improving IR in obese and T2DM subjects [47-49]. Similarly, decreased GDF-8 levels after chronic exercise training were observed in both healthy control and PCOS women. GDF-8 treatment suppresses adipocyte differentiation by inhibiting lipid accumulation and promoting the secretion of lipolytic enzymes [50]. GDF-8 inhibition in skeletal muscle improves dyslipidemia and insulin sensitivity thereby preventing the development of diabetes in lipodystrophy mouse model [51]. The reduced GDF-8 levels following chronic exercise training therapy were elevated by the intralipid infusion and insulin infusion reduced GDF-8 levels in PCOS women suggesting a role of GDF8 in insulin sensitivity.

GDF-15 significantly correlated with age and HOMAIR in PCOS women [52]. In this study, GDF-15 was associated positively with LDL-c in healthy control and FPG in PCOS women. In T2DM and obese subjects, chronic exercise training therapy increases circulatory GDF-15. It is associated with increased $\beta$-cell disposition, insulin sensitivity, and fat mass reduction [53, 54], but no significant changes in GDF-15 were observed 
after chronic exercise training. Fasting and a ketogenic diet exacerbates hepatic GDF-15 levels promoting fatty acid oxidation and ketogenesis in the liver mouse model [55]. Fasting is associated with decreased GDF-15 levels, but oral glucose ingestion increased GDF-15 levels back to baseline in both lean and obese human subjects. In HepG2 cells, insulin and glucose significantly stimulated GDF-15 secretion and transcription [56]. Hyperinsulinemia increases circulatory GDF-15 during different stages of adiposity [57]. Co-infusion of intralipids with insulin significantly increased GDF-15 levels in PCOS subjects.

\section{Study strength and limitations}

The major strength was that this is the first study performed in humans to study the relationship between insulin and lipid infusion on circulating CTRP-2, CTRP-9, GDF-8, and GDF-15. This study was an interventional study with a standard methodology for characterizing the PCOS patients with well-supervised exercise that was a significant strength. The smaller study group is one of the limitations of this study; therefore, the results are to be cautiously interpreted. In large cohorts, these sorts of interventional studies will be challenging to perform because of frequent blood sampling during the clamp and multiple visits. Only Caucasians were included as participants, which could have limited the findings of this study.

\section{Conclusion}

This is the first study performed in humans to show that intralipid infusion is a potent stimulator for CTRP-2 in healthy control and PCOS subjects, suggesting that CTRP-2 might have a physiological role in lipid metabolism. The study also shows that 8 weeks of chronic exercise training decreases GDF- 8 in healthy control and PCOS women suggesting that GDF-8 regulation may have a role in adaptation to exercise, and GDF-15 and CTRP-9 may play a role in the insulin response. Based on the findings, it appears that future studies could focus on understanding the relationship between CTRP2 in dyslipidemia. The complex interactions between insulin and intralipids on CTRPs/GDFs in human suggest that these factors play an important role in the overall metabolic responses to metabolic challenges.

\footnotetext{
Abbreviations

ALT: Alanine transaminase; BMI: Body mass index; CTRP: C1Q TNF related protein; DBP: Diastolic blood pressure; FAl: Free Androgen Index; FFA: Free fatty acids; FPG: Fasting plasma glucose; GDF: Growth differentiation factors; HDL: High density lipoprotein; HIEC: hyperinsulinemic-euglycemic clamp; HOMA-IR: Homeostatic model assessment of insulin resistance; LDL: Low density lipoprotein; IR: Insulin resistance; NEFA: Non-esterified fatty acids; OGTT: Oral glucose tolerance test; PCOS: Polycystic ovary syndrome; SBP: Systolic blood pressure; SHBG: Sex hormone binding globulin; T2DM: Type-2 diabetes mellitus; TCH: Total cholesterol; TG: Triglycerides; ITT: Insulin tolerance test; WT: wild-type
}

\section{Acknowledgements}

Open Access funding provided by the Qatar National Library, Qatar. We would like to thank Weill Cornell Medicine, Qatar for the support. The authors would also like to thank Dr. Prem Chandra for helping in statistics.

\section{Authors' contributions}

JJ wrote the manuscript. JJ, RP, and IB performed measurements. JJ and MR helped in reviewing the manuscript. SLA, MMA TS involved in recruitment, collection of samples and data analysis. SS, MA and MR researched the data and contributed to manuscript. MS and SLA conceptualized the study design and finalized the manuscript. ABAS supervised, conceptualized the study design and approved the finalized the manuscript. All the authors reviewed and revised the manuscript.

\section{Funding}

The authors would like to thank Qatar Metabolic Institute \& Medical Research Center, Hamad Medical Corporation for funding this study (Grant number: MRC\#17180/17)

Availability of data and materials

The data are available upon request from the corresponding author.

\section{Declarations}

Ethics approval and consent to participate

All the study participants gave written informed consent, and this study was conducted according to the Good Clinical Practice and Declaration of Helsinki. The study was approved by Medical Research Center, Hamad Medical Corporation (RP \#17180/17) and Yorkshire and Humber Ethics Committee, Leeds (10/H1313/44). ISRCTN number: ISRCTN42448814.

\section{Consent for publication}

All authors gave consent for publication.

\section{Competing interests}

No competing interest declared by the authors.

\section{Author details}

${ }^{1}$ Qatar Metabolic Institute, Department of Medicine and Academic Health System, Hamad Medical Corporation, Doha, Qatar. ${ }^{2}$ Interim Translational Research Institute, Academic Health System, Hamad Medical Corporation, Doha, Qatar. ${ }^{3}$ Department of Academic Endocrinology, Diabetes and Metabolism, Hull York Medical School, Hull, UK. ${ }^{4}$ RCSI Bahrain, Adliya, Bahrain.

Received: 21 November 2020 Accepted: 6 April 2021

Published online: 19 April 2021

\section{References}

1. Sam S. Obesity and polycystic ovary syndrome. Obes Manag. 2007;3(2):6973. https://doi.org/10.1089/obe.2007.0019.

2. Sirmans SM, Pate KA. Epidemiology, diagnosis, and management of polycystic ovary syndrome. Clin Epidemiol. 2013;6:1-13. https://doi.org/1 0.2147/CLEP.S37559.

3. Goyal M, Dawood AS. Debates regarding lean patients with polycystic ovary syndrome: a narrative review. J Hum Reprod Sci. 2017;10(3):154-61. https:// doi.org/10.4103/jhrs.JHRS_77_17.

4. Faloia E, Canibus P, Gatti C, Frezza F, Santangelo M, Garrapa GGM, et al. Body composition, fat distribution and metabolic characteristics in lean and obese women with polycystic ovary syndrome. J Endocrinol Investig. 2004; 27(5):424-9. https://doi.org/10.1007/BF03345285.

5. Akshaya S, Bhattacharya R. Comparative study of clinical profile of lean and obese polycystic ovary syndrome women. Int J Reprod Contracept Obstet Gynecol. 2017;5:4.

6. Rojas J, Chávez M, Olivar L, Rojas M, Morillo J, Mejías J, et al. Polycystic ovary syndrome, insulin resistance, and obesity: navigating the pathophysiologic labyrinth. Int J Reprod Med. 2014;2014:719050.

7. Boumosleh JM, Grundy SM, Phan J, Neeland IJ, Chang A, Vega GL. Metabolic concomitants of obese and nonobese women with features of polycystic ovarian syndrome. J Endocrine Soc. 2017;1(12):1417-27. https:// doi.org/10.1210/js.2017-00323. 
8. Manco M, Castagneto-Gissey L, Arrighi E, Carnicelli A, Brufani C, Luciano R, et al. Insulin dynamics in young women with polycystic ovary syndrome and normal glucose tolerance across categories of body mass index. PLoS One. 2014;9(4):e92995. https://doi.org/10.1371/journal.pone.0092995.

9. Seldin MM, Tan SY, Wong GW. Metabolic function of the CTRP family of hormones. Rev Endocr Metab Disord. 2014;15(2):111-23. https://doi.org/10.1 007/s11154-013-9255-7.

10. Wong GW, Krawczyk SA, Kitidis-Mitrokostas C, Revett T, Gimeno R, Lodish HF. Molecular, biochemical and functional characterizations of C1q/TNF family members: adipose-tissue-selective expression patterns, regulation by PPAR-gamma agonist, cysteine-mediated oligomerizations, combinatorial associations and metabolic functions. Biochem J. 2008;416(2):161-77. https://doi.org/10.1042/BJ20081240.

11. Lei X, Wong GW. C1q/TNF-related protein 2 (CTRP2) deletion promotes adipose tissue lipolysis and hepatic triglyceride secretion. J Biol Chem. 2019; 294(43):15638-49. https://doi.org/10.1074/jbc.RA119.009230.

12. Peterson JM, Seldin MM, Tan SY, Wong GW. CTRP2 overexpression improves insulin and lipid tolerance in diet-induced obese mice. PLoS One. 2014;9(2): e88535. https://doi.org/10.1371/journal.pone.0088535.

13. Jia Y, Luo X, Ji Y, Xie J, Jiang H, Fu M, et al. Circulating CTRP9 levels are increased in patients with newly diagnosed type 2 diabetes and correlated with insulin resistance. Diabetes Res Clin Pract. 2017;131:116-23. https://doi. org/10.1016/j.diabres.2017.07.003.

14. Wolf RM, Steele KE, Peterson LA, Zeng X, Jaffe AE, Schweitzer MA, et al. C1q/TNF-related Protein-9 (CTRP9) levels are associated with obesity and decrease following weight loss surgery. J Clin Endocrinol Metab. 2016; 101(5):2211-7. https://doi.org/10.1210/jc.2016-1027.

15. Shanaki M, Moradi N, Fadaei R, Zandieh Z, Shabani P, Vatannejad A. Lower circulating levels of CTRP12 and CTRP13 in polycystic ovarian syndrome: irrespective of obesity. PLoS One. 2018;13(12):e0208059. https://doi.org/1 0.1371/journal.pone.0208059.

16. Sadeghi A, Fadaei R, Moradi N, Fouani FZ, Roozbehkia M, Zandieh Z, et al. Circulating levels of C1q/TNF-a-related protein 6 (CTRP6) in polycystic ovary syndrome. IUBMB Life. 2020;72(7):1449-59. https://doi. org/10.1002/iub.2272.

17. Kheirollahi A, Teimouri M, Karimi M, Vatannejad A, Moradi N, Borumandnia N, et al. Evaluation of lipid ratios and triglyceride-glucose index as risk markers of insulin resistance in Iranian polycystic ovary syndrome women. Lipids Health Dis. 2020;19(1):235. https://doi.org/10.1186/s12944-020-01410-8.

18. Peterson JM, Wei Z, Seldin MM, Byerly MS, Aja S, Wong GW. CTRP9 transgenic mice are protected from diet-induced obesity and metabolic dysfunction. Am J Physiol Regul Integr Comp Physiol. 2013;305(5):R522-33. https://doi.org/10.1152/ajpregu.00110.2013.

19. Hanna A, Frangogiannis NG. The role of the TGF- $\beta$ superfamily in myocardial infarction. Front Cardiovasc Med. 2019;6:140. https://doi.org/1 0.3389/fcrm.2019.00140.

20. Guo T, Jou W, Chanturiya T, Portas J, Gavrilova O, McPherron AC. Myostatin inhibition in muscle, but not adipose tissue, decreases fat mass and improves insulin sensitivity. PLoS One. 2009;4(3):e4937. https://doi.org/10.13 71/journal.pone.0004937.

21. Lanlan F, Sijia W, Yiran L, Yiping Y, Yuxi L, Yang Y, et al. High GDF-8 in follicular fluid is associated with a low pregnancy rate in IVF patients with PCOS. Reproduction. 2020;160:11-9.

22. Tang M, Luo M, Lu W, Wang S, Zhang R, Liang W, et al. Serum growth differentiation factor 15 is associated with glucose metabolism in the third trimester in Chinese pregnant women. Diabetes Res Clin Pract. 2019;156: 107823. https://doi.org/10.1016/j.diabres.2019.107823.

23. Yang L, Chang C-C, Sun Z, Madsen D, Zhu H, Padkjær SB, et al. GFRAL is the receptor for GDF15 and is required for the anti-obesity effects of the ligand. Nat Med. 2017;23(10):1158-66. https://doi.org/10.1038/nm.4394.

24. Mullican SE, Lin-Schmidt X, Chin C-N, Chavez JA, Furman JL, Armstrong AA, et al. GFRAL is the receptor for GDF15 and the ligand promotes weight loss in mice and nonhuman primates. Nat Med. 2017;23(10):1150-7. https://doi. org/10.1038/nm.4392.

25. Schernthaner-Reiter MH, Itariu BK, Krebs M, Promintzer-Schifferl M, Stulnig TM, Tura A, et al. GDF15 reflects beta cell function in obese patients independently of the grade of impairment of glucose metabolism. Nutr Metab Cardiovasc Dis. 2019;29(4):334-42. https://doi.org/10.1016/j.numecd.2 018.12.008.

26. Ackermann K, Bonaterra GA, Kinscherf R, Schwarz A. Growth differentiation factor-15 regulates oxLDL-induced lipid homeostasis and autophagy in human macrophages. Atherosclerosis. 2019;281:128-36. https://doi.org/10.1 016/j.atherosclerosis.2018.12.009.

27. Aye MM, Butler AE, Kilpatrick ES, Kirk R, Vince R, Rigby AS, et al. Dynamic change in insulin resistance induced by free fatty acids is unchanged though insulin sensitivity improves following endurance exercise in PCOS. Front Endocrinol. 2018;9:592. https://doi.org/10.3389/fendo.2018.00592.

28. Aye MM, Kilpatrick ES, Aburima A, Wraith KS, Magwenzi S, Spurgeon B, et al. Acute hypertriglyceridemia induces platelet hyperactivity that is not attenuated by insulin in polycystic ovary syndrome. J Am Heart Assoc. 2014;3:e000706.

29. Kirk RJ, Madden LA, Peart DJ, Aye MM, Atkin SL, Vince RV. Circulating endothelial microparticles reduce in concentration following an exercise Programme in women with polycystic ovary syndrome. Front Endocrinol. 2019;10:200. https://doi.org/10.3389/fendo.2019.00200.

30. Foster C, Florhaug JA, Franklin J, Gottschall L, Hrovatin LA, Parker S, et al. A new approach to monitoring exercise training. J Strength Cond Res. 2001; 15(1):109-15.

31. Ramanjaneya M, Jerobin J, Bettahi I, Bensila M, Aye M, Siveen KS, et al. Lipids and insulin regulate mitochondrial-derived peptide (MOTS-c) in PCOS and healthy subjects. Clin Endocrinol. 2019;91(2):278-87. https://doi.org/1 0.1111/cen.14007.

32. Halama A, Aye MM, Dargham SR, Kulinski M, Suhre K, Atkin SL. Metabolomics of dynamic changes in insulin resistance before and after exercise in PCOS. Front Endocrinol. 2019;10:116. https://doi.org/10.3389/ fendo.2019.00116.

33. Boden G, Jadali F, White J, Liang Y, Mozzoli M, Chen X, et al. Effects of fat on insulin-stimulated carbohydrate metabolism in normal men. J Clin Invest. 1991;88(3):960-6. https://doi.org/10.1172/JCl115399.

34. Clerk LH, Rattigan S, Clark MG. Lipid infusion impairs physiologic insulinmediated capillary recruitment and muscle glucose uptake in vivo. Diabetes. 2002;51(4):1138-45. https://doi.org/10.2337/diabetes.51.4.1138.

35. Hegyi T, Kleinfeld A, Huber A, Weinberger B, Memon N, Joe Shih W, et al. Effects of soybean lipid infusion on triglyceride and unbound free fatty acid levels in preterm infants. J Matern Fetal Neonatal Med. 2019;32(19):3226-31. https://doi.org/10.1080/14767058.2018.1461827.

36. Amini E, Didban A, Eabrhim B, Hatmi Z. Changes of Total plasma triglycerides in neonates treated with Intralipid: a pilot study. Iran J Pediatr. 2015;25:e256.

37. Wong GW, Wang J, Hug C, Tsao T-S, Lodish HF. A family of Acrp30/ adiponectin structural and functional paralogs. Proc Natl Acad Sci U S A. 2004;101(28):10302-7. https://doi.org/10.1073/pnas.0403760101.

38. Ndefo UA, Eaton A, Green MR. Polycystic ovary syndrome: a review of treatment options with a focus on pharmacological approaches. P T. 2013; 38(6):336-55.

39. Forouhi N, Saedisomeolia A, Djalali M, Eshraghian MR, Morshedzadeh N, Zabetian-Targhi F, et al. Serum C1q and tumor necrosis factor (TNF)-related protein 9 in women with polycystic ovary syndrome. Diabet Metabol Syndrome. 2016;10(2):S131-4. https://doi.org/10.1016/j.dsx.2016.03.012.

40. Ilbeigi D, Khoshfetrat M, Afrisham R, Rahimi B, Gorgani-Firuzjaee S. Serum C1q/TNF-related Protein-2 (CTRP2) levels are associated with coronary artery disease. Arch Med Res. 2020;51(2):167-72. https://doi.org/10.1016/j.arcmed.2 020.01.009.

41. Li Z, Du Y, Jia L, Fan J, Guo R, Ma X, et al. Association of C1q/TNF-related Protein-9 (CTRP9) level with obstructive sleep apnea in patients with coronary artery disease. Mediat Inflamm. 2020;2020:7281391.

42. Wang J, Hang T, Cheng XM, Li DM, Zhang QG, Wang LJ, et al. Associations of C1q/TNF-related Protein-9 levels in serum and Epicardial adipose tissue with coronary atherosclerosis in humans. Biomed Res Int. 2015;2015:971683.

43. Wei Z, Lei X, Petersen PS, Aja S, Wong GW. Targeted deletion of C1q/TNFrelated protein 9 increases food intake, decreases insulin sensitivity, and promotes hepatic steatosis in mice. Am J Phys Endocrinol Metab. 2014; 306(7):E779-90. https://doi.org/10.1152/ajpendo.00593.2013.

44. Arpaci H. Major determinants of circulating myostatin in polycystic ovary syndrome. Exp Ther Med. 2019;17(2):1383-9. https://doi.org/10.3892/etm.201 8.7080 .

45. Chen MJ, Han DS, Yang JH, Yang YS, Ho HN, Yang WS. Myostatin and its association with abdominal obesity, androgen and follistatin levels in women with polycystic ovary syndrome. Hum Reprod. 2012;27(8):2476-83. https://doi.org/10.1093/humrep/des209.

46. Hittel DS, Berggren JR, Shearer J, Boyle K, Houmard JA. Increased secretion and expression of Myostatin in skeletal muscle from extremely obese women. Diabetes. 2009;58(1):30-8. https://doi.org/10.2337/db08-0943. 
47. Hittel DS, Axelson M, Sarna N, Shearer J, Huffman KM, Kraus WE. Myostatin decreases with aerobic exercise and associates with insulin resistance. Med Sci Sports Exerc. 2010;42(11):2023-9. https://doi.org/10.1249/MSS.0b013e31 81e0b9a8.

48. Shabkhiz F, Khalafi M, Rosenkranz S, Karimi P, Moghadami K. Resistance training attenuates circulating FGF-21 and myostatin and improves insulin resistance in elderly men with and without type 2 diabetes mellitus: a randomised controlled clinical trial. Eur J Sport Sci. 2020:1-10. https://doi. org/10.1080/17461391.2020.1762755.

49. Ryan AS, Li G, Blumenthal JB, Ortmeyer HK. Aerobic exercise + weight loss decreases skeletal muscle myostatin expression and improves insulin sensitivity in older adults. Obesity. 2013;21:1350-6.

50. Hui Juan Z, Hui P, Xu Zhe Z, Nai Shi L, Lin Jie W, Hong Bo Y, et al. The effect of myostatin on proliferation and lipid accumulation in 3T3-L1 preadipocytes. J Mol Endocrinol. 2015:54:217-26.

51. Guo T, Bond ND, Jou W, Gavrilova O, Portas J, McPherron AC. Myostatin inhibition prevents diabetes and Hyperphagia in a mouse model of Lipodystrophy. Diabetes. 2012;61 (10):2414-23. https:/doi.org/10.2337/db11-0915.

52. Berberoglu Z, Aktas A, Fidan Y, Canan Yazici A, Aral Y. Plasma GDF-15 levels and their association with hormonal and metabolic status in women with polycystic ovary syndrome aged 25-35. Minerva Endocrinol. 2014;39(2):89-97.

53. Zhang H, Mulya A, Nieuwoudt S, Mcdowell R, Kirwan JP. GDF15 Is a Contraction-Induced Myokine That Regulates Pancreatic B-Cell Function. Diabetes. 2018:67:67.

54. Zhang H, Fealy CE, Kirwan JP. Exercise training promotes a GDF15associated reduction in fat mass in older adults with obesity. Am J Physiol Endocrinol Metabol. 2019;316(5):E829-36. https://doi.org/10.1152/ajpendo. 00439.2018

55. Zhang M, Sun W, Qian J, Tang Y. Fasting exacerbates hepatic growth differentiation factor 15 to promote fatty acid $\beta$-oxidation and ketogenesis via activating XBP1 signaling in liver. Redox Biol. 2018;16:87-96. https://doi. org/10.1016/j.redox.2018.01.013.

56. Schernthaner-Reiter MH, Kasses D, Tugendsam C, Riedl M, Peric S, Prager G, et al. Growth differentiation factor 15 increases following oral glucose ingestion: effect of meal composition and obesity. Eur J Endocrinol. 2016; 175(6):623-31. https://doi.org/10.1530/EJE-16-0550.

57. Karczewska-Kupczewska M, Kowalska I, Nikolajuk A, Adamska A, Otziomek E, Gorska M, et al. Hyperinsulinemia acutely increases serum macrophage inhibitory cytokine-1 concentration in anorexia nervosa and obesity. Clin Endocrinol. 2012;76(1):46-50. https://doi.org/10.1111/j.1365-2265.2011.04139.x

\section{Publisher's Note}

Springer Nature remains neutral with regard to jurisdictional claims in published maps and institutional affiliations.

Ready to submit your research? Choose BMC and benefit from:

- fast, convenient online submission

- thorough peer review by experienced researchers in your field

- rapid publication on acceptance

- support for research data, including large and complex data types

- gold Open Access which fosters wider collaboration and increased citations

- maximum visibility for your research: over $100 \mathrm{M}$ website views per year

At $\mathrm{BMC}$, research is always in progress.

Learn more biomedcentral.com/submissions 